\title{
Assessment of Practice and Outcome of Exercise on Quality of Life of Women with Breast Cancer in Delta State
}

\author{
Linda C Odikpo*, Edith N Chiejina
}

\begin{abstract}
Objectives: This study evaluated the effect of exercise on the quality of life of women with breast cancer. It determined the pre and post-intervention functional, symptoms, and global quality of life of women with breast cancer in the control and intervention groups. Methods: The quasi-experimental design study adopted a purposive sampling technique in selecting the women with breast cancer in the intervention (47) and control (47) groups. Data on QOL was measured using standardized instruments, namely the European Organization for Research and Treatment of Cancer Quality of Life Questionnaire-version 3 (EORTC QLQ-C30. Results: The results show the pre-intervention overall functional quality of life domain score was 59.2 \pm 21.98 for the intervention and $67.0 \pm 20.13$ for the control, an overall score for the symptom domain was $31.8 \pm 10.89$ for the intervention and $29.8 \pm 10.24$ for the control. The post-intervention overall generic functional domain score was $89.0 \pm 11.1$ for the intervention and $51.2 \pm 17.8$ for the control and for symptoms domain; their overall score was $16.4 \pm 10.2$ for the intervention and $35.4 \pm 12.4$ for the control. A significant difference existed in all post-intervention functional domain scores of the generic function and symptoms quality of life as the functional domains $(p<0.001)$ and global health status $(p<0.001)$. Conclusion: As the numbers of women who survive breast cancer continue to increase, there is a need for lifestyle modification like exercise to improve and maintain their overall QOL to live a fulfilled life devoid of post-treatment complications.
\end{abstract}

Keywords: Assessment- practice- outcome- exercise- generic quality of life

Asian Pac J Cancer Prev, 22 (8), 2377-2383

\section{Introduction}

Breast cancer is the most common invasive cancer in women, and the second leading cause of cancer deaths in women, after lung cancer (American Cancer Society, 2013). Globally, breast cancer accounts for $45.1 \%$ of all cancers in women and the second leading cause of cancer death among women after lung cancer (Sathian et al., 2014). It is responsible for $23 \%$ of total cancer cases and $14 \%$ of cancer deaths worldwide (Jemal et al., 2011).

Breast cancer is cancer that develops from breast tissue (National cancer institute, 2014). Breast cancers are considered either in situ or invasive (American Cancer Society, 2013). According to the Center for Disease Control (2017), the first symptoms of breast cancer is usually an area of thickened tissue in the breast or a lump in the breast or an armpit. Other symptoms of breast cancer include pain in the armpits or breast that does not change with the monthly cycle, pitting or redness of the skin of the breast like the skin of an orange, a rash around one of the nipples, a discharge from a nipple, possibly containing blood, an inverted nipple, a change in the size or shape of the breast, peeling, flaking and scaling of the skin on the breast or nipple.
Treatment for breast cancer depends on the type of breast cancer, the stage of cancer, sensitivity to hormones, the patient's age, overall health, and preferences. The main treatment options for breast cancer, as outlined by American Institute for Cancer Research (2015), include surgery, radiation therapy, biological therapy, or targeted drug therapy, hormone therapy, and chemotherapy. This diagnostic and treatment process of breast cancer causes patients to have a more inferior quality of life which is negatively associated with the overall well-being of women with breast cancer (Sen et al., 2011; Yildiz et al., 2011; Enache, 2012).

Studies on the quality of life of breast cancer patients show that poor health-related quality of life is always seen in breast cancer patients, especially in rehabilitation and aftercare. The focus is on reducing and improving cancerand treatment-related side effects that do not subside even after the end of the therapy (Mirandola et al., 2014). Other symptoms associated with impaired quality of life include depression and fatigue, and quality of life is impaired not long after adjuvant treatment in breast cancer patients (Mirandola et al., 2014). Most of the problems associated with breast cancer diagnosis and treatment can be reduced or ameliorated with the help of exercise, as exercise has 
been seen to beneficial (Odikpo and Chiejina,2021). This view was supported by Mustian et al., (2017) in an overview of the oncology literature on the use of exercise to restore and improve the quality of life of cancer survivors. Breast cancer survivors in a study also indicated that exercise might have positive effects on their generic quality of life and disease-specific quality-of-life issues, including body image/self-esteem, emotional well-being, sexuality, sleep disturbance, social functioning, anxiety, fatigue, and pain (Vallance et al., 2013). There were also studies demonstrating that exercise was associated with improvements in the symptom of depression, maintenance of body weight, reduction of treatment side effects, body image, self-esteem (Volaklis et al.,2013; Odikpo and Chiejina,2021), and generic quality of life among breast cancer patients (Denlingerand Engstrom, 2011).

From the preceding, it is essential to note that reasonable evidence supports exercise interventions in breast cancer survivors have significant effects on their generic quality of life (QoL) by improving physical and psychological functioning, as discovered by Zeng et al., (2014) and Ferrer et al., (2011). Duncan et al., (2017) also stated that physical exercise interventions (yoga, aerobic, and resistance training) are effective in improving the generic quality of life in cancer survivors despite the prevailing barriers that prevent them from engaging in these health-promoting breast cancer-specific exercises (Odikpo and Chiejina, 2020).

In Nigeria, however, few studies have emerged on the quality of life of women with breast cancer, including a study by Adeoluwa et al., (2007) on health-related quality of life and its determinants in Nigerian breast cancer patients and Folorunsho et al., (2013) on quality of life of people with cancers in Ibadan, Nigeria. Despite the high incidence of breast cancer in Nigeria (Uchendu, 2020), none of these studies has considered exercise intervention and quality of life of breast cancer patients except study by Rufa'I et al., (2019) on Physical Activity and Health-Related Quality of Life in Breast Cancer Patients which was not an intervention study. Hence the need for this present study cannot be overemphasized as it aimed to assess the outcome of exercise on the generic quality of life of women with breast cancer in tertiary hospitals in Delta State, Nigeria. It determined the pre and post-intervention generic functional, symptoms, and global quality of life of women with breast cancer in the control and intervention groups.

\section{Materials and Methods}

The quasi-experimental design study adopted a purposive sampling technique in selecting the women with breast cancer in the intervention (47) and control (47) groups. It involved a pre-test, exercise intervention for the intervention group, and post-test data collection. The pre-test was carried out to collect baseline information on women's quality of life with breast cancer in the intervention and control groups before exercise intervention was implemented for the intervention group. After the intervention, the post-test was conducted to assess the effect of exercise on women's generic quality of life who participated in the study. The study area was two tertiary hospitals, including the Federal medical center, Asaba, and Delta State university teaching hospital Oghara that manage breast cancer patients in Delta state. The instrument for data collection in the study was divided into two sections; section A was used to elicit information on the demographic characteristics of the women in both groups, while section B was the European Organization for Research and Treatment of Cancer Quality of Life Questionnaire-version 3 [EORTC QLQ-C30] to elicit information on the pre and post-intervention quality of life of the women in both groups before and after the intervention. The generic QOL instrument comprised 30 items and was used to elicit information on the general health status of the respondents before and after exercise intervention. The QOL instrument is designed on a fourpoint scale with Not at all $=1$, Little $=2$, Quite a $b i t=3$, and very much $=4$. Item 29 and 30 consists of a range of seven-point items (1234567) with extremes of poor $=1$ point and excellent $=7$ points. EORTC QLQ-C30 is a standardized instrument; hence, it was not validated but tested for reliability to ensure that it will adapt to our environment. The collected data were analyzed using the Spearman Brown formula for split-half coefficient. The reliability coefficient obtained was 0.85 ; hence the instrument was reliable for the study. The exercise intervention was conducted for the intervention group only with the assistance of the exercise physiotherapist, and the exercises practiced by the participants in the intervention group were warm-up with aerobic baseball and dance, treadmill, Ergometric bicycle riding, shoulder and arm exercises. After the exercise intervention, copies of the QOL questionnaire were re-administered to the two groups to collect post-test data.

The summary of data collected was done using the average of the items that contribute to the scale of the QOL instrument, and hypotheses were tested using an independent sample t-test. The results were presented in Tables. The analysis was done using the Statistical Package for Social Sciences (SPSS) version 17.

\section{Results}

Table 1 shows that the minimum and maximum age of the respondents from Control group was 19years and 63 years respectively, while that of the Intervention group was 30years and 64years. Both groups were mostly Christians [Intervention (89.4\%); Control (95.7\%)], and were married [intervention (70.2\%); control (66.0\%)]. Majority had tertiary education [intervention (57.4\%), control $(46.8 \%)]$, and were employed [intervention (70.2\%); control(51.1\%)]. Majority were diagnosed of breast cancer from 10 months and above for the both group [Intervention (52.2\%); Control (44.7\%)] and stages of which they were diagnosed was majorly stage 1 for the both groups [intervention (57.4\%); control(42.6\%)].

Table 2 above shows the generic functional quality of life of respondents from control and intervention group using EORTC instrument before intervention. For the control group, the functional, based on the reference points, values for role, emotional, cognitive, and social 
DOI:10.31557/APJCP.2021.22.8.2377

Practice and Outcome of Exercise Uptake on the Quality of Life of Breast Cancer Women

Table 1. Socio-Demographic Characteristics of Participants

\begin{tabular}{|c|c|c|c|c|}
\hline Variables & $\begin{array}{c}\text { Intervention } \\
\text { group }(\%)\end{array}$ & $\begin{array}{c}\text { Control } \\
\text { group (\%) }\end{array}$ & $\begin{array}{c}\mathrm{X}^{2} \\
\text { value }\end{array}$ & $\begin{array}{c}\mathrm{p} \\
\text { value }\end{array}$ \\
\hline \multicolumn{5}{|l|}{ Age category } \\
\hline Maximum age & 64 & 63 & & \\
\hline Minimum age & 30 & 19 & - & - \\
\hline Mean \pm SD & $44 \pm 8.0$ & $45.0 \pm 9.0$ & & \\
\hline \multicolumn{5}{|l|}{ Marital status } \\
\hline Married & $33(70.2)$ & $31(66.0)$ & & \\
\hline Single & $6(12.8)$ & $8(17.0)$ & 0.6 & 0.896 \\
\hline Widow & $5(10.6)$ & $4(8.5)$ & & \\
\hline Divorced/separated & $3(6.4)$ & $4(8.5)$ & & \\
\hline \multicolumn{5}{|l|}{ Level of education } \\
\hline No formal education & $3(6.4)$ & $4(8.5)$ & & \\
\hline Primary education & $2(4.3)$ & $6(12.8)$ & 2.7 & 0.448 \\
\hline Secondary education & $15(31.9)$ & $15(31.9)$ & & \\
\hline Tertiary education & $27(57.4)$ & $22(46.8)$ & & \\
\hline \multicolumn{5}{|l|}{ Religion } \\
\hline Christian religion & $42(89.4)$ & $45(95.7)$ & & \\
\hline Islamic religion & $5(10.6)$ & $1(2.1)$ & 3.8 & 0.152 \\
\hline Traditional religion & $0(0.0)$ & $1(2.1)$ & & \\
\hline \multicolumn{5}{|l|}{ Occupation } \\
\hline Unemployed & $0(0.0)$ & $6(12.7)$ & & \\
\hline Self employed & $14(29.8)$ & $17(36.2)$ & 7.7 & $0.021 *$ \\
\hline Employed & $33(70.2)$ & $24(51.1)$ & & \\
\hline \multicolumn{5}{|l|}{ Cancer diagnosis } \\
\hline \multicolumn{5}{|c|}{ When were you diagnosed of breast cancer? } \\
\hline ess than 3 months & $1(2.1)$ & $1(2.1)$ & & \\
\hline 3 to 6 months & $5(10.9)$ & $7(14.9)$ & & \\
\hline 7 to 9 months & $17(37.0)$ & $18(38.3)$ & 0.6 & 0.905 \\
\hline 10 month and above & $24(52.2)$ & $21(44.7)$ & & \\
\hline \multicolumn{5}{|c|}{ At what stage were you diagnosed of breast cancer } \\
\hline Stage1 & $27(57.4)$ & $20(42.6)$ & & \\
\hline Stage 2 & $5(10.6)$ & $12(25.5)$ & & \\
\hline Stage 3 & $1(2.1)$ & $0(0.0)$ & & \\
\hline Stage 4 & $11(23.4)$ & $13(27.7)$ & 5.3 & 0.259 \\
\hline Not sure & $3(6.4)$ & $2(4.3)$ & & \\
\hline
\end{tabular}

functions were found to be within the reference value at $56.3 \pm 27.2,65.6 \pm 19.5,77.6 \pm 21.5$ and $68.4 \pm 41.4$ respectively while physical functioning was low at 58.5 \pm 19.9 . On symptoms, pain, dyspnoea, and, appetite loss and constipation were within the acceptable ranges at $39.5 \pm 12.3,28.4 \pm 31.1,17.0 \pm 27.6$, and $12.8 \pm 27.4$ respectively. However, symptoms such as nausea and vomiting, insomnia, diarrhoea and financial difficulties were quite high at $22.6 \pm 16.4,46.0 \pm 32.3,3.5 \pm 12.4$ and $53.9 \pm 35.8$ respectively. Meanwhile the global health
Table 2. Pre-Intervention Generic QOL of Women with Breast Cancer

\begin{tabular}{lccc}
\hline Domain/Scales & $\begin{array}{c}\text { Intervention } \\
\mathrm{M} \pm \mathrm{SD}\end{array}$ & $\begin{array}{c}\text { Control } \\
\mathrm{M} \pm \mathrm{SD}\end{array}$ & $\begin{array}{c}\text { Reference } \\
\text { scores }\end{array}$ \\
\hline Functional domain & & & \\
Physical functioning & $55.8 \pm 21.6$ & $58.5 \pm 19.9$ & $\geq 66.7$ \\
Role functioning & $47.2 \pm 22.3$ & $56.3 \pm 27.2$ & $\geq 50$ \\
Emotional functioning & $60.2 \pm 19.8$ & $65.6 \pm 19.5$ & $\geq 50$ \\
Cognitive functioning & $67.3 \pm 28.4$ & $77.6 \pm 21.5$ & $\geq 66.7$ \\
Social functioning & $62.0 \pm 40.0$ & $68.4 \pm 41.4$ & $\geq 66.7$ \\
Overall functional score & $59.2 \pm 21.98$ & $67.0 \pm 20.13$ & \\
Symptoms domain & & & \\
Fatigue & $43.5 \pm 17.4$ & $44.9 \pm 17.9$ & $11.1-44.4$ \\
Nausea and vomiting & $24.8 \pm 11.4$ & $22.6 \pm 16.4$ & $0-0$ \\
Pain & $44.0 \pm 15.7$ & $39.5 \pm 12.3$ & $\leq 50$ \\
Dyspnoea & $36.2 \pm 31.7$ & $28.4 \pm 31.1$ & $\leq 33.3$ \\
Insomnia & $43.3 \pm 31.0$ & $46.0 \pm 32.3$ & $\leq 33.3$ \\
Appetite loss & $6.3 \pm 14.9$ & $17.0 \pm 27.6$ & $\leq 33.3$ \\
Constipation & $11.3 \pm 26.2$ & $12.8 \pm 27.4$ & $\leq 33.3$ \\
Diarrhea & $14.0 \pm 28.4$ & $3.5 \pm 12.4$ & $0-0$ \\
Financial difficulties & $61.7 \pm 33.3$ & $53.9 \pm 35.8$ & $\leq 33.3$ \\
Overall symptoms & $31.8 \pm 10.89$ & $29.8 \pm 10.24$ & \\
score & & & $\geq 50$ \\
Global health & $53.0 \pm 17.0$ & $40.0 \pm 10.3$ & \\
status/QoL (revised) & & & \\
\hline
\end{tabular}

Physical func Q1-5, role func Q6,7, emotional func Q21-24, cognitive func Q20,25, social func Q26,27). Symptoms domain (fatigue Q10,12,18, nausea/vomiting Q14,15, pain Q9,19, dyspnoea Q8, insomnia Q11, appetite loss Q13, constipation Q16, diarrhea Q17, financial difficulties Q28).

status which shows the overall quality of life was low at $40.0 \pm 10.3$.

For intervention group, the functions, based on the reference points, values for emotional and cognitive, were found to be within the reference values at $60.2 \pm 19.8$ and $67.3 \pm 28.4$ respectively while physical, role and social functioning were low at $55.8 \pm 21.6,47.2 \pm 22.3$ and $62.0 \pm 40.0$.

On symptoms, fatigue, pain, dyspnoea, and, appetite loss and constipation were within the acceptable ranges at $43.5 \pm 17.4,44.0 \pm 15.7,6.3 \pm 14.9$ and $11.3 \pm 26.2$ respectively. However, symptoms such as nausea and vomiting, dyspnoea, insomnia, diarrhoea and financial difficulties were quite high at $24.8 \pm 11.4,36.2 \pm 31.7$, $43.3 \pm 31.0,14.0 \pm 28.4$ and $61.7 \pm 33.3$ respectively. Meanwhile the global health status which show the overall QOL was fair at $53.0 \%$ although is few values above the border reference value. The overall functional quality of life was $59.2 \pm 21.98$ for the intervention and $67.0 \pm 20.13$ for the control and overall score for the symptom domain

Table 3. Practice of Exercise Observed by the Researcher for the Intervention Group of Women with Breast Cancer

\begin{tabular}{lllll}
\hline Modality of exercises practiced & Number of weeks & Duration & Intensity & Notable side effect \\
\hline Aerobic -dance, warm up with & $<12$ weeks 14(29.8) & Aerobic 10-30munites 47(100) & moderate & Headache \\
base ball, & $>12$ weeks 33 (70.2) & Resistance 10-20munites & 47(100) & Dizziness \\
Resistance - threadmill and & & $47(100)$ & Mild syncope & $1(8.5)$ \\
Ergometric bicycle riding & & Flexibility 10-20munites & None \\
flexibility- shoulder and arm & & $47(100)$ & $39(83.0)$ \\
exercises & & &
\end{tabular}


Table 4. Post Intervention Generic QOL of Women with Breast Cancer

\begin{tabular}{|c|c|c|c|}
\hline Domain/Scales & $\begin{array}{c}\text { Intervention } \\
\mathrm{M} \pm \mathrm{SD}\end{array}$ & $\begin{array}{l}\text { Control } \\
\mathrm{M} \pm \mathrm{SD}\end{array}$ & $\begin{array}{l}\text { Reference } \\
\text { score }\end{array}$ \\
\hline \multicolumn{4}{|l|}{ Functional domain } \\
\hline Physical functioning & $89.1 \pm 15.3$ & $45.4 \pm 24.3$ & $\geq 66.7$ \\
\hline Role functioning & $88.7 \pm 15.2$ & $57.1 \pm 25.9 *$ & $\geq 50$ \\
\hline Emotional functioning & $92.5 \pm 14.7$ & $52.8 \pm 26.4 *$ & $\geq 50$ \\
\hline Cognitive functioning & $92.2 \pm 12.5$ & $59.1 \pm 21.4^{*}$ & $\geq 66.7$ \\
\hline Social functioning & $82.6 \pm 23.0$ & $41.5 \pm 27.9$ & $\geq 66.7$ \\
\hline Overall functional score & $89.0 \pm 11.1$ & $51.2 \pm 17.8$ & - \\
\hline \multicolumn{4}{|l|}{ Symptoms domain } \\
\hline Fatigue & $13.5 \pm 15.2$ & $44.9 \pm 17.8$ & $11.1-44.4$ \\
\hline Nausea and vomiting & $6.0 \pm 13.6$ & $32.9 \pm 28.9$ & $0-0$ \\
\hline Pain & $12.4 \pm 14.9$ & $42.6 \pm 22.7 *$ & $0-50$ \\
\hline Dyspnoea & $5.7 \pm 12.6$ & $14.9 \pm 24.8 *$ & $0-33.3$ \\
\hline Insomnia & $15.5 \pm 27.7$ & $48.2 \pm 22.8$ & $0-33.3$ \\
\hline Appetite loss & $1.9 \pm 4.7$ & $10.6 \pm 6.7^{*}$ & $0-33.3$ \\
\hline Constipation & $17.7 \pm 28.5$ & $27.7 \pm 32.1 *$ & $0-33.3$ \\
\hline Diarrhea & $12.1 \pm 18.9$ & $18.4 \pm 22.8$ & $0-0$ \\
\hline Financial difficulties & $62.4 \pm 32.3$ & $78.7 \pm 27.3$ & 0.33 .3 \\
\hline Overall symptoms score & $16.4 \pm 10.2$ & $35.4 \pm 12.4$ & - \\
\hline $\begin{array}{l}\text { Global health status/QoL } \\
\text { (revised) }\end{array}$ & $73.4 \pm 17.1$ & $48.6 \pm 15.4$ & $\geq 50$ \\
\hline
\end{tabular}

Physical functioning Q1-5, role functioning Q6,7, emotional functioning Q21-24, cognitive functioning Q20,25, social functioning Q26,27). Symptoms domain (fatigue Q10,12,18, nausea/vomiting Q14,15, pain Q9,19, dyspnoea Q8, insomnia Q11, appetite loss Q13, constipation Q16, diarrhea Q17, financial difficulties Q28).

was $31.8 \pm 10.89$ for the intervention and $29.8 \pm 10.24$ for the control.

Table 3 shows the observed practice of exercise by women with breast cancer in the intervention group. Modality of exercises practiced was aerobic 47 (100), resistance 47 (100) and flexibility 47 (100). Majority 33 (70.2) practiced for a period of 12 weeks, and time covered for aerobic 10-30 munites 47 (100), resistance 10-20 munites 47 (100), Flexibility 10-20 munites 47 (100). Intensity of exercise practiced mild and moderate 47 (100), majority did not have any side effects $39(83.0)$

Table 4 presents post intervention generic functional symptom and global quality of life of women with breast cancer. In functional domain, emotional functioning (92.5 \pm 14.7$)$, cognitive functioning $(92.2 \pm 12.5)$, role functioning $(88.7 \pm 15.2)$, physical $(89.1 \pm 15.3)$ and social function (82.6 \pm 23.0 ) was higher for the intervention group of women than the control group, cognitive functioning (59.1 \pm 21.4$)$, and role functioning (57.1 \pm 25.9$)$, physical (45.4 \pm 24.3$)$, emotional (52.8 \pm 26.4$)$ and social functioning (41.5 \pm 27.9$)$ respectively. In symptoms domain, all the symptoms were lesser for the intervention group post intervention than the control group. Global health quality of life for intervention was high and the improvement was remarkable at $(73.4 \pm 17.1)$ and the control group scored $(48.6 \pm 15.4)$. The overall generic functional quality of life was $89.0 \pm 11.1$ for the intervention and $51.2 \pm 17.8$ for the control and for symptoms domain, their overall
Table 5. Independent Sample t-test of Difference in Generic Functional, Symptoms and Global Quality of Life of Women with Breast Cancer who Practiced and Those who Did Not

\begin{tabular}{lcccc}
\hline Domain/Scales & $\begin{array}{c}\text { Intervention } \\
\mathrm{M} \pm \mathrm{SD}\end{array}$ & $\begin{array}{c}\text { Control } \\
\mathrm{M} \pm \mathrm{SD}\end{array}$ & $\mathrm{T}$ & $\mathrm{p}$-value \\
\hline Functional domain & & & & \\
Physical functioning & $89.1 \pm 15.4$ & $45.4 \pm 24.3$ & 10.426 & $<0.001$ \\
Role functioning & $88.7 \pm 15.2$ & $57.1 \pm 25.9$ & 7.196 & $<0.001$ \\
Emotional functioning & $92.6 \pm 14.8$ & $52.8 \pm 26.4$ & 9.009 & $<0.001$ \\
Cognitive functioning & $92.2 \pm 12.5$ & $59.2 \pm 21.4$ & 9.14 & $<0.001$ \\
Social functioning & $82.6 \pm 23.0$ & $41.5 \pm 28.0$ & 7.779 & $<0.001$ \\
Overall functional score & $89.0 \pm 11.1$ & $51.2 \pm 17.8$ & 12.353 & $<0.001$ \\
Symptoms domain & & & & \\
Fatigue & $13.5 \pm 15.2$ & $44.9 \pm 17.8$ & -9.217 & $<0.001$ \\
Nausea and vomiting & $6.0 \pm 13.6$ & $33.0 \pm 29.0$ & -5.769 & $<0.001$ \\
Pain & $12.4 \pm 14.9$ & $42.6 \pm 22.7$ & -7.596 & $<0.001$ \\
Dyspnoea & $5.7 \pm 12.7$ & $14.9 \pm 24.9$ & -2.265 & 0.027 \\
Insomnia & $15.6 \pm 27.7$ & $48.2 \pm 22.9$ & -6.232 & $<0.001$ \\
Appetite loss & $2.0 \pm 4.7$ & $10.6 \pm 6.7$ & -7.268 & $<0.001$ \\
Constipation & $17.7 \pm 28.5$ & $27.7 \pm 32.1$ & -1.585 & 0.116 \\
Diarrhea & $12.1 \pm 18.9$ & $18.4 \pm 22.9$ & -1.474 & 0.144 \\
Financial difficulties & $62.4 \pm 32.3$ & $78.7 \pm 27.3$ & -2.644 & 0.01 \\
Overall symptoms score & $16.4 \pm 10.2$ & $35.4 \pm 12.4$ & -8.113 & $<0.001$ \\
Global health status/QoL & $73.4 \pm 17.1$ & $48.6 \pm 15.4$ & 7.404 & $<.001$ \\
\hline
\end{tabular}

score was $16.4 \pm 10.2$ for the intervention and $35.4 \pm 12.4$ for the control.

Table 5 revealed significant difference existed in all the functional domain of the generic quality of life as the intervention group had higher functional quality of life than the control group in all the functional

Table 6. Independent Sample t-test of Comparison of Generic Functional, Symptoms and Global Quality of Life of Women in the Control and Intervention Group Pre-Intervention

\begin{tabular}{|c|c|c|c|c|}
\hline Domain/scales & $\begin{array}{c}\text { Intervention } \\
\mathrm{M} \pm \mathrm{SD}\end{array}$ & $\begin{array}{l}\text { Control } \\
\mathrm{M} \pm \mathrm{SD}\end{array}$ & $\mathrm{t}$ & $\begin{array}{c}\mathrm{p}- \\
\text { value }\end{array}$ \\
\hline \multicolumn{5}{|l|}{ Functional domains } \\
\hline Physical functioning & $55.9 \pm 21.6$ & $58.6 \pm 19.9$ & -0.628 & 0.531 \\
\hline Role functioning & $47.2 \pm 22.3$ & $56.4 \pm 27.3$ & -1.793 & 0.076 \\
\hline Emotional functioning & $60.3 \pm 19.8$ & $65.6 \pm 19.6$ & -1.31 & 0.194 \\
\hline Cognitive functioning & $67.4 \pm 28.4$ & $77.7 \pm 21.5$ & -1.978 & 0.051 \\
\hline Social functioning & $62.1 \pm 40.0$ & $68.4 \pm 41.4$ & -0.759 & 0.45 \\
\hline Overall functional score & $58.6 \pm 18.8$ & $65.3 \pm 17.0$ & -1.812 & 0.073 \\
\hline \multicolumn{5}{|l|}{ Symptoms domain } \\
\hline Fatigue & $43.5 \pm 17.5$ & $44.9 \pm 17.9$ & -0.388 & 0.699 \\
\hline Nausea and vomiting & $24.8 \pm 11.5$ & $22.7 \pm 16.5$ & 0.727 & 0.469 \\
\hline Pain & $44.0 \pm 15.7$ & $39.5 \pm 12.4$ & 1.53 & 0.13 \\
\hline Dyspnoea & $36.2 \pm 31.7$ & $28.4 \pm 31.1$ & 1.205 & 0.231 \\
\hline Insomnia & $43.3 \pm 31.0$ & $46.1 \pm 32.3$ & -0.435 & 0.665 \\
\hline Appetite loss & $6.4 \pm 15.0$ & $17.0 \pm 27.7$ & -2.317 & 0.023 \\
\hline Constipation & $11.3 \pm 26.3$ & $12.8 \pm 27.4$ & -0.256 & 0.798 \\
\hline Diarrhea & $14.9 \pm 28.5$ & $3.5 \pm 12.5$ & 2.5 & 0.015 \\
\hline Financial difficulties & $61.7 \pm 33.3$ & $53.9 \pm 35.8$ & 1.093 & 0.277 \\
\hline Overall symptoms score & $31.8 \pm 10.9$ & $29.8 \pm 10.2$ & 0.918 & 0.361 \\
\hline Global health status/QoL & $53.0 \pm 17.1$ & $40.1 \pm 10.4$ & 4.444 & $<.001$ \\
\hline
\end{tabular}


domains $(\mathrm{p}<0.001)$ and global health status $(\mathrm{p}<.001)$. Significant difference also existed in the symptoms quality of life as the control group had significantly higher symptoms than the intervention group except for constipation $(p=0.116)$ and diarrhea $(p=0.144)$, which were not significant.

Table 6 shows significance difference did not exist in all the functional domains of generic quality of life. For symptoms domain, significant difference existed only in appetite loss $(\mathrm{p}=0.023)$ and diarrhoea $(\mathrm{p}=0.015)$, with appetite loss being higher in the control and diarrhoea higher in the intervention. Significance difference also existed in global health status $(\mathrm{p}<0.001)$.

\section{Discussion}

Pre-intervention functional, symptoms and global status of the generic quality of life of women with breast cancer in the control and intervention groups shows the functional quality of life of the women with breast cancer in the control and intervention groups, apart from the low physical functioning, other functions were comparable to the reference values (Table 2). On symptoms, their symptoms were relatively high, and the overall global health status, which is the overall quality of life, was low for both groups of women. However, the intervention group had a score that is up to the minimal level of the reference point. This result on the quality of life considering the overall global health status/ QOL is poor, especially for women in the control group compared to the reference value of EORTC QOL. Hence, the overall QOL of women who participated in the study was inadequate for the control and fair for the intervention group, respectively. This finding is similar to Mirandola et al., (2014) and Yabroff et al., (2008), who stated that poor health-related quality of life is always seen in breast cancer patients, especially aftercare. However, a study by Muhammad et al., (2019) showed Global health status and functional scales, showing better QoL, although the symptoms were also on the high side, which is similar to that of the findings of this study. Also, a related study by Amarsheda and Bhise (2021) revealed that the breast cancer subscale score in QOL had a lower value than others, although the social well-being score was higher.

The study also revealed high financial difficulty among the women in both groups. Corroborating this result, Breast cancer.org (2018) stated that breast Cancer Causes Long-Term Financial Burden for Many People, especially those With Lymphedema. Leez (2020) also stated that women with breast cancer battle with "Financial toxicity" — the cost-related side effects borne by cancer patients who take a huge emotional, mental and physical toll. Maggi (2020) and Spencer (2019) stressed that a similar financial burden said that women with breast cancer might likely change due to the illness, thereby posing more financial challenges. Jessica (2020) and Nahid et al., (2020) also reiterated that breast cancer survivors reported worsening financial status and distress after being diagnosed. There is, therefore, the need for emotional, financial, and physical support for these patients, and it is essential to state that with the current financial burden, all other aspects of generic QOL may be affected, thereby complicating the health of the women with breast cancer.

On the post-intervention generic functional, symptoms, and global quality of life of the control and intervention groups of women with breast cancer, for the control group, results show that most of the functional scales were low when placed side to side with the reference values. Most of the symptoms experienced were still high, and the global quality of life was still not up to the reference point. Hence, there was no remarkable improvement between the pretest and post-test results of the women in the control group who were not subjected to exercise intervention. On the post-intervention result of the intervention group regarding their generic functional, symptoms, and global quality of life, results show a remarkable improvement on all the domains of the generic QOL after the intervention. The exercise intervention improved the generic QOL of women with breast cancer in the intervention group, thereby agreeing with findings in a study by Margaret et al. (2015); David and Cynthia (2015). Hence, exercise had a beneficial effect on the generic QOL of life of breast cancer patients who participated in the study.

The hypotheses show a significant difference across all the functions, symptoms, and global health status between the two groups. For the functional domain and global health status, statistically significant improvement was observed across the scales for women who practiced exercise compared to those who did not. For the symptoms, a statistically significant decrease was observed in the values for women who practiced exercise compared to those who did not practice. Based on the preceding, the researcher rejected the hypothesis as it was evident that a lot of difference exists between the women from the intervention group who had the exercise intervention and the women from the control group who had none regarding all the domains of the generic QOL Domains. This finding was similar to report in a similar study by Ferrer et al., (2011). The result also supports evidence result that exercise interventions in breast cancer survivors have significant effects on generic quality of life(QoL) by improving the overall well-being of breast cancer patients (Zeng et al., 2014)

The pre-intervention hypotheses to show if a significant difference existed in the pre-intervention QOL of the participants in both groups revealed no significant difference in any of the functions between the women in the intervention and control groups pre-intervention. However, the researchers found few of the symptoms and global quality of life to differ within institutions, although the difference was not highly significant, thereby supporting evidence-based results by Muhammad et al., (2019) and Tahani et al., (2019). The latter saw similarity on issues that affect females with breast cancer.

Based on the findings of this study, there is a need for urgent attention to be paid to the rehabilitation need of women with breast cancer, especially by those that care for them. Breast cancer patients should educate them on the need for exercise and its implication on their health primarily to ensure they have an improved and sustained generic QOL after their treatment. The exercise program should be specific and tailored to their need hence; there 
is a need to use recommended exercise guidelines, which can be adapted to meet the local context and need of the individual breast cancer patient and other cancer patients in general.

In conclusion, breast cancer has been a public health issue. As the numbers of women that survive breast cancer continue to increase, there is a need for lifestyle modification like exercise may improve and maintain the generic QOL of the sufferers so that they can live a fulfilled life devoid of post-treatment complications.

\section{Author Contribution Statement}

All the authors contributing to the study from the beginning to the end of the study. Odikpo did manuscript drafting, while Chiejina supervised the process of the research till the end

\section{Acknowledgments}

Authors acknowledge the institutions where the researchers domiciled-Nnamdi Azikiwe University Awka as the study is part of an approved student dissertation. The breast cancer survivors that participated in the study are at this moment acknowledged.

\section{Availability of data}

Data about the study is available with the corresponding author and will be provided upon reasonable request

\section{Ethical consideration}

Ethical approval was obtained from the Health Research Ethics Committee of the two tertiary hospitals involved in the study.

\section{Conflict of interest}

Authors declare no conflict of interest.

\section{References}

Adeoluwa J, Sofela EA, Adamu AR (2007). Health related quality of life and its determinants in Nigerian breast cancer patients. Afr J Med Health Sci, 36, 259- 65.

Amarsheda S, Bhise A (2021). Association of fatigue, quality of life and functional capacity in breast cancer patients receiving adjuvant chemotherapy. Asian Pac J Cance Care, 6, 59-64.

American Cancer Society .(2013). Definition of breast cancer and cancer treatment. CA Cancer J Clin Med, 56, 323-53.

Breast cancer.org (2018). Breast cancer causes long-term financial burden for many people, especially those with lymphedema. https://www.breastcancer.org/research-news/ bc-causes-financial-burden-for-many (Retrieved 23rd May, 2019).

Center for Disease Control and Prevention (2017). National Health Interview Surveys, 2000 and 2015. Public Use Data Files 2001. Atlanta, GA. (Retrieved 20th August 2018). https://www.cdc.gov/nchs/nhis/shs/tables.htm.

David OG, Cynthia AT (2015). Physical activity and cancer survivorship in the United States. Nutr Clin Pract, 29, 768-79.

Denlinger CS, Engstrom PF (2011).Cancer survivorship: movement matters. Cancer Prev Res, 4, 502-11.
Duncan M, Moschopoulou E, Herrington E, et al (2017). SURECAN Investigators: Review of systematic reviews of non-pharmacological interventions to improve quality of life in cancer survivors. BMJ Open, 2017, e015860

Enache RG (2012). The relationship between anxiety, depression and self-esteem in womenwith breast cancer after surgery. SBSPRO, 33, 124-7.

Ferrer RA, Huedo-Medina TB, Johnson BT, Ryan S, Pescatello LS (2011). Exercise interventions for cancer survivors: a meta-analysis of quality of life outcomes. Ann Behav Med, 41, 32-47.

Folorunsho N, Kazeem A, Olurotimi A (2013). Quality of life of people with cancers in Ibadan, Nigeria. $J$ Ment Health, 22, DOI: 10.3109/09638237.2012.734644

Jemal A, Bray F, Center MM, Ferlay J, Ward E, Forman D(2011). Global cancer statistics. CA Cancer J Clin, 61, 69-90

Jessica N, Semin D, Palm LM, Smith, Sarah R (2020). Understanding breast cancer survivors' financial burden and distress after financial assistance. Support Care Cancer, 28, 4241-8.

Liz (2020) The financial burden of breast cancer. https://www. forbes.com/sites/nextavenue/2020/01/21/the-financialburden-of-breast-cancer/?sh=48bbe7394d21 (Retrieved 27th August, 2020).

Maggie I (2020). Economic Burden of Breast Cancer: Greatest Impact on Rural and Black Women. Medpage Today. https:// www.medpagetoday.com/resource-centers/spotlight-her2positive-breast-cancer/economic-burden-breast-cancergreatest-impact-rural-and-black-women/2761(https://www. forbes.com/sites/nextavenue/2020/01/21/the-financialburden-of-breast-cancer/?sh=48bbe7394d21 (Retrieved 27th August, 2020).

Margaret L (2015). Effects of exercise on breast cancer patients and survivors: a systematic review and meta-analysis. Curr Onco, 22, 374-84

Mirandola D, Miccinesi G, Muraca MG, et al (2014).Evidence for adapted physical activity as an effective intervention for upper limb mobility and quality of life in breast cancer survivors. J Phys Act Health, 11, 814-22.

Muhammad, Rolina, Shadi, Mukhtia, Bashayer (2019). Assessment of quality of life (QoL) in breast cancer patients: A tertiary care center survey in the western region of Saudi Arabia. PLoS One, 14.

Mustian KM, Alfano CM, Heckler C (2017). Comparison of pharmaceutical, psychological, and exercise treatments for cancer-related fatigue: a meta-analysis. JAMA Oncol, 3, 961-8.

Nahid H, Vahid K, Asiyeh S, Hamidreza R (2014). The financial cost of preventive and curative programs for breast cancer: A Case Study of Women in Shiraz-Iran. Int J Health Policy Manag, 2, 187-91

Odikpo Lc, Chiejina En(2020) Assessment of barriers to practice of exercise among women with breast cancer in Delta State. Breast J, 11, 2305-7

Odikpo Lc, Chiejina En (2021). Knowledge and perceived benefits of exercise among women with breast cancer in Tertiary Hospitals in Delta State. Breast Dis, 1-8 (Pre-Print)

Rufa'i AA, V Muralikrishna BV, Yen SH, Wan-Muda WM (2019). Physical activity and health-related quality of life in breast cancer patients: A Multicenter Cross-Sectional Survey. Middle East J Rehabil Health Stud, 6, e89858.

Sathian B, Nagaraja, SB, Banerjee I, et al (2014). Awareness of breast cancer warning signs and screening methods among female residents of Pokhara valley, Nepal. Asian Pac J Cancer Prev, 15, 4723-26.

Sen F, Aydiner A (2011). Depending on the late side effects of cancer treatment. J Clin Dev, 24, 30-2. 
Spencer JC, Rotter JS, Eberth JM, et al (2019). Employment changes following breast cancer diagnosis: the effects of race and place. J Natl Cancer Inst, pii, djz197. doi: 10.1093/ jnci/djz197. [Epub ahead of print].

Tahani HN, Huda RE, Aisha OG, Arwa AO, Raid (2019). Quality of life assessment of breast cancer patients in Saudi Arabia. PLoS One, 26, 98-102.

Uchendu O (2020). Cancer incidence in Nigeria: A Tertiary Hospital Experience. Asian Pac J Cance Care, 5, 27-32.

Vallance JK, Courneya KS, Plotnikoff RC, Yasui Y, Mackey JR (2013). Randomized controlled trial of the effects of print materials and step pedometers on physical activity and quality of life in breast cancer survivors. J Clin Oncol, 25, 2352-9

Volaklis KA, Halle M, Tokmakidis SP (2013). Exercise in the prevention and rehabilitation of breast cancer. Wien Klin Wochenschr, 125, 297-301.

Yabroff KR, Lamont EB, Mariotto A, et al (2008). Cost of care for elderly cancer patients in the United States. J Natl Cancer Inst, 100, 630-4.

Yildiz A, Karayurt O (2011). Women with breast cancer lymphedema due to the difficulties in which they live. Breast Health J, 7, 154-62.

Zeng YC, Huang ML, Cheng A, Zhou Y, So WK (2014). Meta-analysis of the effects of exercise intervention on quality of life in breast cancer survivors. J Breast Cancer, 21, 262-74.

This work is licensed under a Creative Commons AttributionNon Commercial 4.0 International License. 